\title{
A GEOGRAFIA FÍSICA NOS ANOS INICIAIS DO ENSINO FUNDAMENTAL: A ALFABETIZAÇÃO CARTOGRÁFICA E SUAS CONTRIBUIÇÕES PARA LEITURA DO ESPAÇO
}

\author{
Bruna Karolina Machado Toledo ${ }^{(a)}$ André dos Santos Ribeiro ${ }^{(b)}$ Gilmara Maria Gonçalves ${ }^{\text {(c) }}$ \\ Kéllys Antunes dos Santos ${ }^{(d)}$ \\ (a) Centro de Ensino Superior em Gestão, Tecnologia e Educação - FAI, tbrunakarolina @ yahoo.com.br \\ (b) Centro de Ensino Superior em Gestão, Tecnologia e Educação - FAI, andreribeiro@ fai-mg.br \\ (c) Centro de Ensino Superior em Gestão, Tecnologia e Educação - FAI, gilmara20032002@ yahoo.com.br \\ (d) Centro de Ensino Superior em Gestão, Tecnologia e Educação - FAI, kellysantunessantos@gmail.com
}

\section{Eixo: GEOGRAFIA FÍSICA: CURRÍCULO, FORMAÇÃO E PRÁTICAS DE ENSINO}

\begin{abstract}
Resumo
O aprendizado da geografia é necessário e importante já durante as séries iniciais. Mas, para que os conhecimentos sejam significativos é necessário que a criança aprenda a ler o espaço. Tal leitura exige muitas condições, que trazem à tona a necessidade de ser realizada uma alfabetização cartográfica, que considere o aprendizado do saber olhar, observar, descrever, registrar e analisar o espaço. Desta forma, o mapa será mais uma possibilidade de leitura de mundo, de apreensão de fenômenos físicos e humanos e da interação dos dois. Com vistas a contribuir tanto com a alfabetização cartográfica quanto com a leitura da paisagem, foi elaborada uma sequência didática envolvendo imagens de satélite e um jogo de quebra-cabeça. Tal atividade articulou teoria e prática e contribuiu com a formação das discentes bolsistas do PIBID/FAI e dos alunos das escolas públicas envolvidas.
\end{abstract}

Palavras chave: PBID; FAI; Santa Rita do Sapucaí; Alfabetização Cartográfica; Quebra-cabeça.

\section{Introdução}

O aprendizado da geografia é necessário e importante já durante as séries iniciais, por dois motivos, descritos por Callai (2010), conhecer e compreender o mundo de maneira sistematizada e construir as bases para aprendizagens futuras. Neste contexto, a Geografia auxilia no aprendizado relacionado a observação e análise do espaço e a interpretação dos fenômenos que estão espacializados.

Desta maneira, a geografia escolar contribui com conhecimentos significativos para a vida dos sujeitos que aprendem a pensar o espaço. Mas, para que isso ocorra é necessário que a criança aprenda a ler o espaço, para que ela possa perceber e se reconhecer. Tal leitura exige muitas condições, que trazem à tona a necessidade de ser realizada uma alfabetização cartográfica, que considere o aprendizado do saber olhar, observar, descrever, registrar e analisar o espaço. Neste sentido, a alfabetização cartográfica significa aprender a operar signos com significados específicos, que permitem a leitura do mundo por meio da leitura do mapa. O mapa é mais uma ferramenta para a leitura do mundo. (CALLAI, 2010). 
O estudo da linguagem cartográfica possui demasiada importância e, como descrito em Brasil - PCN (1997), contribui não apenas para que os alunos compreendam e utilizem os mapas, uma ferramenta básica da Geografia, como também para que desenvolvam capacidades relativas à representação do espaço. Porém Simielli (2001) destaca que os mapas devem estar adaptados aos usuários e que é necessária a diferenciação e seleção feita pelo professor de elementos que os alunos têm condições de ler e compreender.

A partir de então, levando em conta principalmente a faixa etária, Simielli (2001) propõe que no ensino fundamental anos iniciais deve ser trabalhado basicamente a alfabetização cartográfica, já que este é o momento em que o aluno tem que iniciar a compreensão dos elementos da representação gráfica para posteriormente trabalhar com a representação cartográfica. Assim sendo, a autora propõe que tal alfabetização seja desenvolvida a partir de noções de visão oblíqua e vertical, de imagem bidimensional e tridimensional, de alfabeto cartográfico (ponto, linha e área), de legenda, de proporção e escala, de lateralidade/referências e de orientação.

Desta forma, o mapa será mais uma possibilidade de leitura de mundo, de apreensão de fenômenos tanto dos aspectos físicos e humanos, quanto da interação dos dois.

Neste contexto, emerge o Sensoriamento Remoto, suas técnicas, métodos, produtos e sínteses. A incorporação do Sensoriamento Remoto ao contexto escolar, pode proporcionar a interação do aluno com questões espaciais, humanas e ambientais do meio em que vive. Santos e Pereira Filho (2010) descrevem que a ampliação do enfoque dado a paisagem local e ao espaço vivido através do emprego de imagens de satélite possibilita a inserção de novo instrumental para o ensino e à socialização do sensoriamento remoto. Se devidamente utilizadas, as imagens de satélite são recursos didático-pedagógicos. $\mathrm{O}$ aspecto colorido, a possibilidade de ver espaços como o vivido sob uma ótica diferente e de acompanhar as mudanças ocorridas na superfície terrestre de maneira instantânea, por si só são capazes de promover no aluno a motivação inicial necessária a todo processo de aprendizagem (SANTOS; PEREIRA FILHO, 2010).

Assim, a partir de reflexões sobre a o papel da Geografia nos anos iniciais do ensino fundamental e da motivação como elemento motriz da aprendizagem, foi desenvolvida uma prática pedagógica voltada à alfabetização cartográfica e identificação de elementos naturais e culturais da paisagem. Estas foram desenvolvidas em turmas de $5^{\circ}$ ano de três escolas públicas da rede de ensino do Município de Santa Rita do Sapucaí, sul de Minas Gerais. Tal proposta esteve alinhada aos objetivos gerais do Programa Institucional de Bolsas de Iniciação à Docência (PIBID), da Coordenação de Aperfeiçoamento de Pessoal de Nível Superior (CAPES), detalhados no endereço <http://www.capes.gov.br/educacao- 


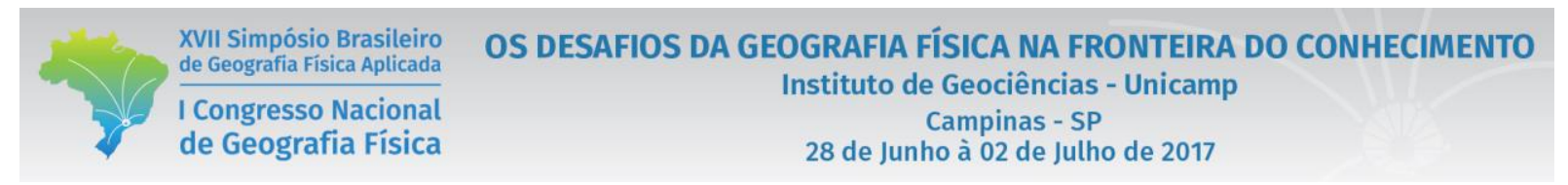

basica/capespibid/pibid>, na qual buscou-se contribuir com a formação das discentes bolsistas graduandas em Pedagogia licenciatura, com a formação dos alunos das turmas envolvidas e com desenvolvimento de materiais e possibilidades para dinamizar a prática pedagógica no ensino de Geografia.

\section{Materiais e Métodos}

A atividade foi planejada como sequência didática pelo coordenador da área de alfabetização cartográfica e foram aplicadas e avaliadas por três discentes bolsistas PIBID do último ano do curso de Pedagogia da FAI (Centro de Ensino Superior em Gestão, Tecnologia e Educação) entre 14/09 e 28/09 de 2016. Para tanto, foram estabelecidas parcerias com escolas da rede pública de ensino de Santa Rita do Sapucaí, município do sul de Minas Gerais.

Tal atividade consistia na montagem de um quebra-cabeça de uma imagem de satélite feita de uma área do município em questão (Figura 1). Envolveu os conteúdos relacionados a perspectiva, proporção, lateralidade, referenciais e orientação espacial, novas tecnologias e representações de espaços do cotidiano, tabelas, paisagem rural e urbana e elementos naturais e culturais. Cabendo destacar o desenvolvimento das habilidades de distinguir e relacionar elementos da paisagem natural e cultural local em imagens de satélite.

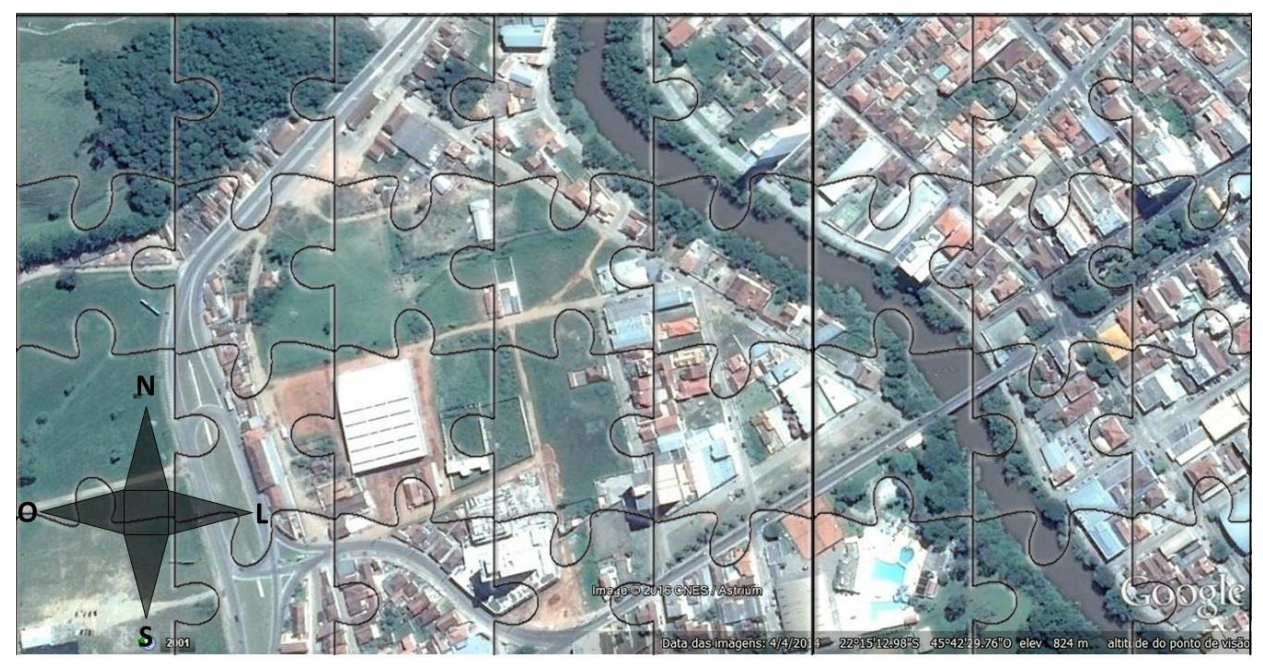

Figura 1 - Quebra-cabeça de imagem de satélite do aplicativo Google Earth feita do município de Santa Rita do Sapucaí no ano de 2016.

A realização da sequência didática foi sistematizada em um plano com detalhes sobre os procedimentos de ensino, dividido em três fases: motivação, com o diálogo inicial baseado nas experiências dos alunos no contato com este tipo de imagem; aplicação do jogo, montagem do quebra-cabeça, diálogos e 
socialização; e, por fim, distinção de elementos da paisagem, organizados em uma tabela na qual foram preenchidos os elementos rurais e urbanos, naturais e culturais.

No total, as bolsistas foram inseridas em turmas do $5^{\circ}$ ano de três instituições de ensino: na Escola Estadual Luiz Pinto de Almeida, na Escola Estadual José Ribeiro de Carvalho e na Escola Municipal Coronel Joaquim Inácio.

Os alunos das escolas foram avaliados pelas discentes bolsistas durante a aplicação da sequência didática e, após, todas relataram suas experiências, para refletirem, sintetizarem e documentarem a prática. A estrutura do relato continha: Apresentação, Objetivos, Desenvolvimento, Discussão e Considerações Finais.

\section{Resultados}

A aplicação da sequência didática foi proveitosa tanto para as discentes bolsistas, que aprofundaram seus conhecimentos nos conteúdos e adquiriram experiência para lidar com a prática, quanto para os alunos das escolas envolvidas, num total de 76 alunos, dentre os quais apenas 4 não desenvolveram todas as habilidades trabalhadas.

Após a aplicação da sequência didática "Quebra-cabeça Imagem de Satélite de Santa Rita do Sapucaí", ilustrada na Figura 3, uma discente bolsista PIBID, relatou que os alunos reconheceram o local representado pela imagem de satélite, do qual foi feito o quebra-cabeça. Indo além, identificaram elementos concretos da paisagem local como as casas, a rodovia, o rio, as árvores, as pastagens, dentre outros. Houveram, porém, dificuldades relacionadas à montagem, haja vista o pouco ou nenhum contato destes alunos com imagens deste tipo e a semelhança entre muitas peças. Assim, foram disponibilizadas imagens da área como suporte para que pudessem completar o jogo.

Outra discente bolsista do Pibid relatou que foi proporcionado aos alunos um momento para trabalherem em grupo e o desempenho foi satisfatório. Cabe ressaltar que para montar o quebra cabeça cada grupo utilizou uma estratégia, alguns observaram mais as cores, outros foram relacionando cada peça com a imagem pronta, alguns pediram ajuda e outros foram começando por partes estratégicas como a rosa dos ventos e o escrito no rodapé do quebra cabeça. Houve intensa troca de conhecimentos e ajuda entre os alunos. Com essa experiência os alunos participaram ativamente, a montaram o quebra-cabeça e, a partir disso, compreenderam que a imagem retrata a paisagem do muncípio que residem e foi feita por um satélite em perspectiva vertical (Figura 2). Nela os alunos identificaram os elementos solicitados e preencheram uma tabela, diferenciando o urbano do rural e os elementos naturais dos culturais. 

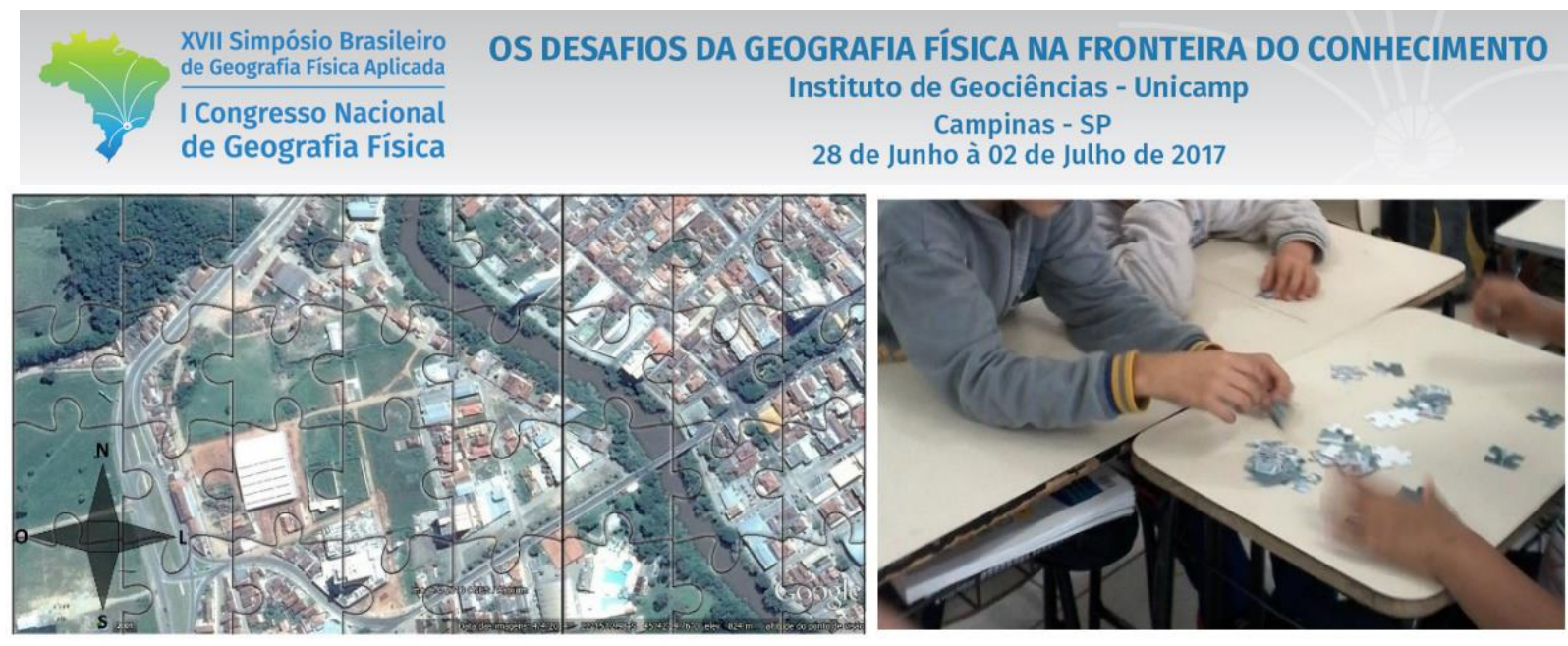

Figura 2 - Imagem do Quebra-cabeça feito a partir de uma imagem de satélite de parte do município de Santa Rita do Sapucaí - MG e fotografia feita no dia 21/09/2016 em uma turma do $5^{\circ}$ ano do ensino fundamental da E. M. Dr. José Ribeiro de Carvalho, ilustrando a montagem e interação dos alunos.

\section{Considerações Finais}

As ações de alfabetização cartográfica realizadas pelo PIBID da FAI nas escolas pelas discentes bolsistas cumpriram a finalidade de articular teoria e prática, aliando os princípios aqui expostos à pratica pedagógica no cotidiano das escolas da rede pública. Assim, alguns desafios foram superados, como articular os códigos cartográficos à leitura dapaisagem em seus aspectos físicos e culturais. Isto aconteceu porque os alunos foram envolvidos ativamente nas fases propostas.

Este é um exemplo de ação que auxilia na elevação da qualidade da formação das discentes do curso de Pedagogia, que desenvolveram conhecimentos mais aprofundados sobre cartografia e ambiente.

\section{REFERÊNCIAS}

BRASIL - PCN. Ministério da Educação e do Desporto - MEC. Secretaria da Educação Fundamental - SEF. Parâmetros Curriculares Nacionais: Geografia. Brasília: MEC/SEF, 1997.

CALLAI, H. C. Espaço, cotidiano e lugar. In: BUITONI, M. M. S (coord.). Coleção Explorando o Ensino: Geografia Ensino Fundamental. Brasília: Ministério da Educação, Secretaria de Educação Básica. 2010. 252 p.

SANTOS, F. C.; PEREIRA FILHO, W. O. Uso de Imagens de Satélite como Recurso Didático para o Estudo da Categoria Lugar. Geo UERJ, v. 2, n. 21. 2010.

SIMIELLI, M. E. R. Cartografia no ensino fundamental e médio. In: CARLOS, A. F. A. (org.). A geografia na sala de aula. 3. ed. São Paulo: Contexto, 2001. 